\title{
Replacing Cinder Gravel as Alternative Base Course Material
}

\author{
Fisseha Wagaw Maniyazawal \\ Department of Civil Engineering, College of Engineering and Technology, Bonga University, Bonga, Ethiopia
}

\section{Email address:}

fishta.maniyazawal62@gmail.com

\section{To cite this article:}

Fisseha Wagaw Maniyazawal. Replacing Cinder Gravel as Alternative Base Course Material. American Journal of Construction and Building Materials. Vol. 4, No. 1, 2020, pp. 14-21. doi: 10.11648/j.ajcbm.20200401.13

Received: January 2, 2020; Accepted: March 9, 2020; Published: March 24, 2020

\begin{abstract}
Costs relating to haulage and processing of materials have considerable impact upon economics of road construction. Hence material search is generally restricted to about $10 \mathrm{~km}$ corridor centering on the road but materials found at this distance may not satisfy the required quality. Cinder gravels are most abundant materials found in tropical countries like Ethiopia especially in rift valley zones where there are active volcanoes. The main objective of the study was to investigating use of cinder gravels as base course material through blending with conventional base course material, CSA, and stabilization with cement. According to results of sieve analysis, ACV, flakiness index and CBR, 30\% of CSA can be replaced by cinder gravels for use as GB1 material and for cement treated cinder gravels adding $6 \%$ and $8 \%$ cement make them suitable for use as CB2 and CB1 base course materials respectively, referring to their 14 day compressive strength as determined by UCS test while the mix with $10 \%$ cement satisfies US Army specification. Based on the results of the research, it is recommended that utilization of the locally available cinder gravels shall be given due consideration for upcoming road construction projects in the study area or in other locations with similar characteristics.
\end{abstract}

Keywords: Marginal Materials, Cinder Gravel, Conventional Material, CSA, Cement Treated, GB1, UCS, CB1 and CB2

\section{Introduction}

The function of road pavement is to provide a safe, comfortable, convenient and economical running surface for the passage of fast-moving traffic. [10] Its structure must be capable of spreading the wheel loads to a level acceptable to the native soil on which it is constructed. Road pavements are constructed in a series of horizontal layers of different materials. Each layer has a specific function and the appropriate materials also the layer thickness has to be selected with regard to efficiency and economy. Materials to be used as unbound granular base materials shall be free from vegetation, lamps, or excessive amount of clay and other objectionable substance. These materials should not contain flat, elongated pieces and dirt. [10] Pavement base course have generally been desired to be dense graded so that they achieve the maximum density and strength. The quality of the base depends on factors like: [13]

a. Gradation

b. Angularity of the particles

c. Shape of the particles (flat and elongated particles should be avoided)

d. Soundness of the aggregate particles

e. Resistance to weathering

f. Hardness of the aggregate particles

g. Moisture content and compaction level

In our country materials to be used for base course construction have been specified which mainly include crashed stone and natural river gravels. However, availability of good quality aggregate may be a problem in some locations and there is future risk of getting this scares material which can support fast growing road infrastructure construction.[5] this is needed to improve poor road network density which retains economic development especially in rural areas of Ethiopia.

Cinder gravels are pyroclastic materials associated with recent volcanic activity. They occur in characteristically straight sided cone shaped hills. Largest cinder cones extending up to a height of $100 \mathrm{~m}$ can be a source of about one million metric tons of cinder gravel. Problems associated with cinder gravels are lack of finer materials in comparison to standard specification and having weak particles that can be 
broken easily which make them unsuitable for base course construction. $[1,4]$

\section{Materials}

\subsection{Base Course Materials}

Base course is the main structural layer of a flexible pavement whose function is to support the applied wheel stress and strains incident on it which is coming from traffic and distribute the same in such a manner that the materials beneath it will not become overloaded. [10] Besides this other functions of base course include resistance to the built up of permanent deformation within each layer, provision of an adequately stiff layer on which the overlaying layers can be compacted and provision of an adequately durable and stiff layer to support any overlaying layers in the long term during in service conditions. [39]

Materials used for base course layer construction shall consist of hard, durable, tough and strong particles or fragments of stone which must be resistant to carry load imposed on them during construction and design life. They must have mechanical interlocking stability, must be resistance to mineralogical change and physical break down due to any cyclic environmental change. [4]

Materials acquiring Suitable for base course construction have been labeled by ERA as standard materials designated as GB1, GB2, GB3 and GB2A with certain specification of grading, shape and minimum strength.

Table 1. Desirable properties of unbound granular materials to be used for base construction.

\begin{tabular}{lll}
\hline Code & Description & Summary of Specification \\
\hline \multirow{2}{*}{ GB1 } & Fresh, crushed rock & Dense graded, un-weathered crushed stone, non-plastic parent fines. \\
GB2 & $\begin{array}{l}\text { Crushed weathered rock, gravel or boulders } \\
\text { ACV }<29 \%, \text { TFV }>111 \mathrm{KN}, \text { FI }<30 \%\end{array}$ \\
GB3 & $\begin{array}{l}\text { Natural coarsely graded granular material, including processed and } \\
\text { modified gravels }\end{array}$ & Dense grading, PI $<6$, soil or parent fines \\
GS & Natural gravel & Dense grading, PI $<6$ CBR after soaking $>80$ \\
GC & Gravel or gravel-soil & CBR after soaking $>30$ \\
\hline
\end{tabular}

$\mathrm{GB}=$ Granular base course, $\mathrm{GS}=$ Granular sub-base, $\mathrm{GC}=$ Granular capping layer. FI- Flakiness index .

\subsection{Marginal Materials}

The gap-graded materials are difficult to compact, increased risk of deformation under traffic, increased moisture susceptibility and pumping of fines. The aggregate bases with high fines content are susceptible to loss of strength and load supporting capability upon wetting. [11] Base aggregate may be considered marginal in terms of shape if it is not only too flaky or elongated but also if its particles are over-rounded with no angular faces. Rounded with smooth surface texture have poor inter-particle friction and loss of stability, compaction difficulty, low density and high air voids content and low stability. Marginal base materials often lead to distress and can lead to premature failure in the form of severe shrinkage cracking followed by accelerated fatigue cracking and a general loss of stability. [23] In Ethiopia marginal materials have been successfully used in for pavement layers even though their use is restricted to low volume roads (T1 T2). Some of these materials are lateritic soils, calcareous, and volcanic rocks. [1, 2] Soft aggregates having very poor crushing resistance can be used as pavement construction material by improving them through mechanical or chemical stabilization. [9, 3] Cinder gravels having weak particles are one of these and proved to be used as construction of base course layer in roads having low volume of traffic and gravel roads. Both ERA and AACRA recommend the use of locally available materials to reduce cost and environmental effect provided that the suitability of the material has been checked by local experimental investigation. ERA suggest that they can be used for highly trafficked roads given that their performance have been tested locally. [3, 4]

\subsubsection{Cinder Gravels}

Cinder gravels are pyroclastic materials associated with recent volcanic activity which occur in characteristically straight sided cone shaped hills. Cinder cones frequently have large concave depressions on their tops or sides where mixtures of solid and gasses were released during the formation of the cones. Cones are commonly found in groups and can extend to a height of 100 meters and generate about 1 million metric ton of cinder gravel. Particles size of this material may reach up to $0.5 \mathrm{~m}$ in diameter. Volcanic cinder generally has a rough surface and high porous nature, with its pores chiefly in the form of vesicles instead of the more tube like, interconnected pores of the pumice. [6, 1] Scoria aggregate (cinder gravels) is found extensively in Ethiopia especially in the great rift valley, which crosses the northeastern part of the country. The study conducted in joint venture by Ethiopian road authority and transport and research laboratory (UK) indicated that volcanic cinder gravels are extensively found in Ethiopia especially in rift valley areas including Akaki, Bishoftu, mojo, Lake Ziway, Lake Chamo, Woliso, Butajira, Bekoji, loggia and Nazareth. [1]

\subsubsection{Properties of Cinder Gravels}

Cinder gravels vary in size and color and their color can be black, red, gray or brown usually with in the same cone. The black color is mostly due to its high iron content while the red color is caused by oxidation of iron in the scoria, which might have happened because of rainfall during the eruption. Color of cinder doesn't have significance effect on their properties. The difference in their properties is attributed to:

a. Initial deposition of the cone and, 
b. The way they have been modified since their depositions. $[1,4,5]$.

Cinder gravels have weak particles which can be easily broken down and they are coarser materials in their natural state. Compaction produces finer particles although this may lead to reducing the required amount of coarser particles. This property makes them difficult to be compacted to a stable layer. [1] The material has moderate durability, high porosity and CBR value well less than that is required to be used as base course material for heavily trafficked roads. Besides their availability they have the advantages of being easily dug out using simple hand tools like mechanical shovel after opening up a working surface using bulldozer.

\subsection{Previous Works on Cinder Gravels}

\subsubsection{Location and Engineering Properties of Cinder Gravels in Ethiopia}

They concentrated on the occurrence and use of cinders. In this study they define cinder gravels in the context of our country and conduct mapping after location survey using aerial photographs, they also study the physical and chemical characteristics of this materials. In order to assure their performance as road construction materials a full-scale experiment was designed and conducted on selected sections of road (Debrezeit - Bekoji). The over - all contents and outcomes of the studies are described below. [2]

\subsubsection{Engineering Properties}

These display a wide range of grading the materials taken from weathered zone are usually too-coarse and contain insufficient fine material for use as road base material. Their coarse particles are relatively soft and were found to possess dry modified aggregate impact values in the range 46 to 100 . On soaking no loss in strength occurred. In the past because of these properties they were rejected for use in road base construction. In addition, they were also reported to be difficult to compact and when compacted they possessed an open texture or a loose surface which was considered unacceptable for surfacing. However, investigations of the use of cinders in existing gravel roads showed that an improvement in grading occurred as a result of particle break-down caused by traffic. In order to examine more closely the role of particle breakdown and grading on their behavior, laboratory compaction studies were conducted using normal falling-rammer methods these found that improvements to their grading occurred.

\subsection{Stabilization}

Stabilization refers to improving the physical and engineering properties of certain material so as to make it suitable for our desired purpose to be an alternative to standard material. Soils that do not possess the desired characteristics for a particular construction reduce pavement life and can be improved by adding stabilizers. Aggregate stabilization is a proven pavement construction technique which utilizes local aggregates to enable pavement construction at often significantly reduced costs and without adversely affecting the pavement's performance. [15]

The general goal is to reduce the volume of interstitial voids, fill empty voids, and improve bonding between the soil grains. In this way better mechanical properties, reduced porosity, limited dimensional changes, and enhanced resistance to normal and severe exposure conditions can be achieved. The principal factors to be considered when selecting the most suitable method of treatment are as follows as indicated by. [35]

a. Type of material to be treated

b. Climatic conditions

c. Type and availability of stabilizers

d. Proposed use of the stabilize material

e. The capabilities and experience of the construction personnel

f. The availability of specialist construction plant

g. The availability of testing facilities for investigation and subsequent quality control Relative costs

There are three most common categories of stabilization techniques. These are physical, mechanical and chemical stabilization. [3, 5, 8]

\subsubsection{Mechanical Stabilization}

Mechanical stabilization involves compressing the soil particles together to increase density and reduce porosity. Compaction is best achieved when the grain size distribution of a soil is continuous, not uniform or gap graded. The presence of grains of different sizes facilitates the occupation of voids left by other soil particles. Unfortunately, the effect of mechanical stabilization when used alone is easily reversed, especially when the soil comes into contact with water. [29] Water causes the lubrication the soil grains, forcing them to move about within the otherwise dandified but still unbound fabric when the material becomes saturated. It therefore follows that in addition to densification, the use of a binder will normally be required mainly to overcome the reversible effect of contact with water. [30]

\subsubsection{Physical Stabilization}

Involves modification of soil properties by introducing the missing size fractions. The texture of a soil can be altered by calculated and controlled mixing of the different fractions together. When this is done, most of the voids that existed prior to physical stabilization are closed due to closer packing of the grains. An anisotropic network is created limiting the movement of the grains in a soil. [28] Unfortunately, as was the case with mechanical stabilization, the effect of physical stabilization alone is not permanent. on saturation with water, soil grains are easily dispersed, or washed away. For better results, physical stabilization of soil should therefore be combined with the other two methods.

\subsubsection{Chemical Stabilization}

Chemical stabilization involves the addition of a binder or bonding agent to a soil (aggregates). The binder modifies the soil properties through cementation or linkage of its particles. Both cementation and linkage are a result of chemical reactions involving the binder and water. Cementation creates 
a strong and inert matrix that can appreciably limit movement in a soil. The voids in the soil are also filled with insoluble by-products of the hydration reaction while some soil particles are coated and firmly held together by the binder. [28] The effect of chemical stabilizations more permanent, and may take several years or even decades to partially reverse. For this reason, chemical stabilization of soil is so far considered to be the superior method of choice.

i. Selection of Stabilizing Agent

Determining the best suited stabilizing agent will to a great extent affect the effectiveness of stabilization process. Selection of stabilizers can be performed based on plasticity, particle size distribution and also considering the constructability aspect.

Table 2. Guide to selection of stabilizer type which is more likely to be effective [3].

\begin{tabular}{|c|c|c|c|c|c|c|}
\hline \multirow{3}{*}{ Type of stabilization } & \multicolumn{6}{|c|}{ Soil properties } \\
\hline & \multicolumn{3}{|c|}{ More than $25 \%$ passing the $0.075 \mathrm{~mm}$ sieve } & \multicolumn{3}{|c|}{ Less than $25 \%$ passing the $0.075 \mathrm{~mm}$ sieve } \\
\hline & $\mathbf{P I} \leq \mathbf{1 0}$ & $10<\mathrm{PI} \leq 20$ & $\mathbf{P I}>\mathbf{2 0}$ & $\mathbf{P I} \leq 6$ & $\mathbf{P I} \leq \mathbf{1 0}$ & $\mathrm{PI}>\mathbf{1 0}$ \\
\hline Cement & Yes & Yes & Note 1 & Yes & Yes & Yes \\
\hline Lime & Note 1 & Yes & Yes & No & Note 1 & Yes \\
\hline Lime-Pozzolan & Yes & Note 1 & No & Yes & Yes & Note 1 \\
\hline
\end{tabular}

\section{ii. Cement Stabilization}

The role of cement is to improve the engineering properties of available soil such as strength, compressibility, permeability, swelling potential, frost susceptibility and sensitivity to changes in moisture content. When water is added to neat cement, the major hydration products are calcium silicate hydrates, calcium aluminate hydrates, and hydrated lime. Cementation is primarily by means of adhesion bonding of the calcium silicate and aluminate hydrates to the rough mineral surfaces. [35] Cement can be successfully used to stabilize a wide range of soils. However, it is particularly well suited to stabilize well graded soils that contain sufficient amount of fines to effectively fill the available voids space and float the coarse aggregate particles. Silty soils (A-2-4 to A-4) and granular materials have been documented to derive the highest degree of improvement (when stabilized with Portland cement) among the soils amenable for cement stabilization. Most soil types, except those with high organic content, highly plastic clays and poorly reacting sandy soils, are amenable to stabilization with Portland cement. [32]

iii.Initial Cement Content

The first step in determining the required cement content is to classify the soil, AASHTO M 145. The criteria for cement percentage required for stabilization shall be as follows. The following methodology shall be used for quality control and soil-cement stabilization.

Perform the mechanical and physical property tests of the soils.

Select the cement content based on the following:

iv. Compressive Strength of Cement Treated Material

The physical property to which reference is made most frequently is compressive strength. The UCS test is the most common test performed on cement is stabilized materials to determine the suitability of the mixtures for uses such as in pavement bases and sub -bases, stabilized subgrades, and structural fills. Although this may not be the most important characteristic of soil cement, many of the factors which influence compressive strength also influence other properties such as durability, flexural strength, shear strength and modulus of elasticity. [32] Most state highway agencies use the UCS test for their mix designs and for quality assurance and quality control because of the simplicity of the test. The UCS test is well established and meets all cost, practicality and availability requirements. Tensile strength can be estimated conservatively as $10 \%$ of the UCS. [18] Detail of the test will be discussed in the methodology chapter.

v. Durability

Durability can be evaluated in terms of expansion, loss of mass, residual strength or change of strength, or swelling, various soundness tests using chemicals like sodium and wet dry and freeze - thaw cycles. AASHTO and American air force design manuals tend to use wet - dry durability test for choosing optimum or design cement content. As with other physical properties, the resistance to wetting and drying and freezing and thawing is dependent upon soil type, cement content, molding water content, density, length of mixing time, and age. [28] Some studies stated that the aforementioned method time taking and unreliable and also UCS test can equivalently be used to indicate the durability of cement stabilized low plasticity soils. [31] ERA include the durability of stabilized materials for road construction by setting design values of compressive strength as determined after 7 days soaking of specimens which had been moist cured for 7 days.

vi. Curing

In flexible base courses, drying shrinkage can lead to both transverse and longitudinal cracks. Such cracks frequently reflect through to the pavement surface. Severe shrinkage cracking can have major detrimental effects on the stiffness of the cement-treated layer, and thus on its structural performance and should be mitigated in the design process. [14] Soil-cement was observed to increase in compressive strength with time of curing with a better than random correlation in both a semi-logarithmic and logarithmic manner. From the test of various types of soils representing ages up to five years, indications are that for granular soil-cement (A-I, A-2, and A-3 soil) the best relationship is semi-logarithmic. [34] This is similar to the relationship observed in concrete whose constituents are similar to granular soil-cement. Silty or clayey soil-cement (A-4, A-5, and A-6 and A-7 soils) on the other hand, exhibits the closest relationship logarithmically.

\section{Methodology}

\subsection{Study Design}

The research will follow experimental type of study which 
begins by collecting samples. The stages involved in the study include: Taking samples, Preparation of samples for each laboratory tests, test characterization for natural untreated cinder material and CSA samples, process blending cinder gravel with CSA and chemical stabilization for determination of cement content to be added in cinder gravel.

\subsection{Material Sampling and Preparation}

Sampling method is purposive so cinder gravel samples were collected from three different areas namely Sallo, Tullu dimtu and Debrezeit which will remain from now on through the paper as their designation in this research for result analysis. Representative Samples were collected in accordance with AASHTO T-2 methodology for sampling from stock piles. Samples of cinder gravel were taken in increments taking care weathered material not to be included. Crushed stone aggregate were supplied by ERCC ordinary Portland cement was purchased from local construction material shop. Before commencing to testing samples of cinder gravel and crushed stone aggregate were prepared using mechanical splitter to obtain uniform samples for all tests. Details of this procedure can be referred in AASHTO T -248 reducing samples of aggregate to testing size.

\subsection{Laboratory Testing}

The test plan had three phases in order to meet the objectives of the research:
I. Characterization of index properties

i. Sieve Analysis

ii. Atterberg Limits

iii. Compaction

iv. $\mathrm{CBR}$

v. $\mathrm{ACV}$

vi. TFV

vii. Flakiness index

viii. Water absorption

ix. Specific gravity

i. Determination of Optimum cinder gravel

ii. Measure the strength and Durability of soil cement through UCS test

\section{Interpretation Result}

\subsection{Natural Cinder Gravels}

As shown in the table below the gradation of all cinder gravel samples collected from Sallo, Debrezeit and Tullu dimitu or their blended prepared by mixing these samples in equal proportion by volume determined before and after compaction doesn't satisfy the requirements set by ERA. A nominal maximum size of $37.5 \mathrm{~mm}$ was selected because cinder gravels contain more than $10 \%$ particles passing $25 \mathrm{~mm}$ sieve. From the comparison we can conclude that cinder gravels can't be used as a base course material without modifying their property.

Table 3. Comparison of gradation of cinder gravel sample (as determined before compaction) with ERA specification.

\begin{tabular}{llllll}
\hline \multirow{2}{*}{$\begin{array}{l}\text { sieve size } \\
(\mathbf{m m})\end{array}$} & \multicolumn{4}{c}{ percentage passing } & ERA specification \\
\cline { 2 - 5 } & Sallo & Debrezeit & Tullu dimitu & blended cinder gravel & Lower - Upper limits \\
\hline 50.0 & 100.0 & 79.6 & 76.3 & 84.3 & 100.0 \\
37.5 & 91.1 & 79.6 & 64.0 & 76.5 & $95-100$ \\
25.0 & 76.5 & 56.8 & 57.8 & 64.9 & $80-100$ \\
19.0 & 69.3 & 46.7 & 54.8 & 58.8 & $25-40$ \\
9.5 & 43.5 & 24.8 & 49.7 & 41.6 & $25-60$ \\
4.75 & 28.5 & 14.2 & 40.6 & 29.6 & $15-30$ \\
2.36 & 21.9 & 9.3 & 31.0 & 22.3 & $7-19$ \\
0.425 & 12.0 & 4.2 & 10.1 & 9.7 & $5-12$ \\
0.075 & 2.9 & 2.7 & 3.4 & 3.3 & \\
\hline
\end{tabular}

Table 4. Gradation of cinder gravel samples as determined after compaction and their comparison with specification.

\begin{tabular}{|c|c|c|c|c|c|}
\hline \multirow{2}{*}{$\begin{array}{l}\text { sieve size } \\
(\mathrm{mm})\end{array}$} & \multicolumn{3}{|c|}{ percentage passing } & \multicolumn{2}{|r|}{ ERA specification } \\
\hline & Sallo & Debrezeit & Tullu dimitu & Blended cinder gravel & Lower - Upper limits \\
\hline 37.5 & 93.9 & 87.8 & 93.9 & 88.9 & $95-100$ \\
\hline 25 & 91.3 & 62.9 & 88.4 & 82.9 & $80-100$ \\
\hline 19 & 86.2 & 52.3 & 82.4 & 68.5 & $60-80$ \\
\hline 9.5 & 71.3 & 27.3 & 68.9 & 51.4 & $40-60$ \\
\hline 4.75 & 56.1 & 18.0 & 54.1 & 42.0 & $25-40$ \\
\hline 2.36 & 43.1 & 14.2 & 39.1 & 33.6 & $15-30$ \\
\hline 0.075 & 7.9 & 4.6 & 5.0 & 5.8 & $5-12$ \\
\hline
\end{tabular}

Results of $\mathrm{ACV}, \mathrm{TFV}$ and $\mathrm{CBR}$ tests also indicate that cinder gravels have weak particles and low bearing capacity as a result of less shear strength which is a result of their gradation. Results of physical and mechanical tests conducted on cinder gravels presented in table 5 shows that cinder gravel is a weak material and has high water absorption capacity because of its high porosity. The CBR value of the material is low for base course, but satisfies the requirements for sub base course materials. 
Table 5. Summary of results for tests conducted on cinder gravel and CSA samples.

\begin{tabular}{|c|c|c|c|c|c|c|}
\hline Parameter & Sallo & Debrezeit & Tullu-Dimtu & Blended Cinder & CSA & Specification \\
\hline OMC (\%) & 23.56 & 20.6 & 22.6 & 19.44 & 7.6 & NS \\
\hline $\operatorname{MDD}(\mathrm{g} / \mathrm{cc})$ & 1.78 & 1.78 & 1.75 & 1.77 & 2.32 & NS \\
\hline CBR $(\%)$ & 31.3 & 35.8 & 32.8 & 32 & 162.5 & $>100$ \\
\hline Specific Gravity & 2.1 & 2.1 & 2.1 & ND & & $2.5-3.0$ \\
\hline $\mathrm{ACV}(\mathrm{KN})$ & 39 & 33 & 38 & 35 & 18 & $<29$ \\
\hline TFV (KN) & 102 & 107 & 101 & 107 & 230 & $>111$ \\
\hline \multicolumn{7}{|l|}{ ND - Not Determined } \\
\hline NS - Not Specified & & & & & & \\
\hline
\end{tabular}

\subsection{For CSA - Cinder Gravel Blend}

The second specific objective of this research was to determine the optimum amount of cinder gravel which can replace CSA base course material satisfying the criterion set by ERA so as to reduce cost of road construction. The comparison of the test results was made with specifications for GB1 material since the aim of the study was to investigate the possibility of partially replacing CSA, which is considered as GB1 according to ERA, with cinder gravels. Comparison was made with gradation limits for nominal maximum size of $37.5 \mathrm{~mm}$.
CSA - cinder gravel blends up to $40 \%$ cinder gravel by volume satisfies gradation limits established by ERA according to sieve analysis conducted before compaction. Compaction increases this value up to $50 \%$ as a result of additional fine and lesser coarser particles obtained by weak nature of cinder particles. Even if break down of aggregates particles due to construction action and application of heavy load from traffic is not desirable property it tends to make the gradation of CSA - cinder gravel blend. Care should be taken so that this break down of aggregate particles would not produce large amount of above the upper limit.

Table 6. Comparison of gradation of CSA - cinder gravel blends before compaction with ERA specification.

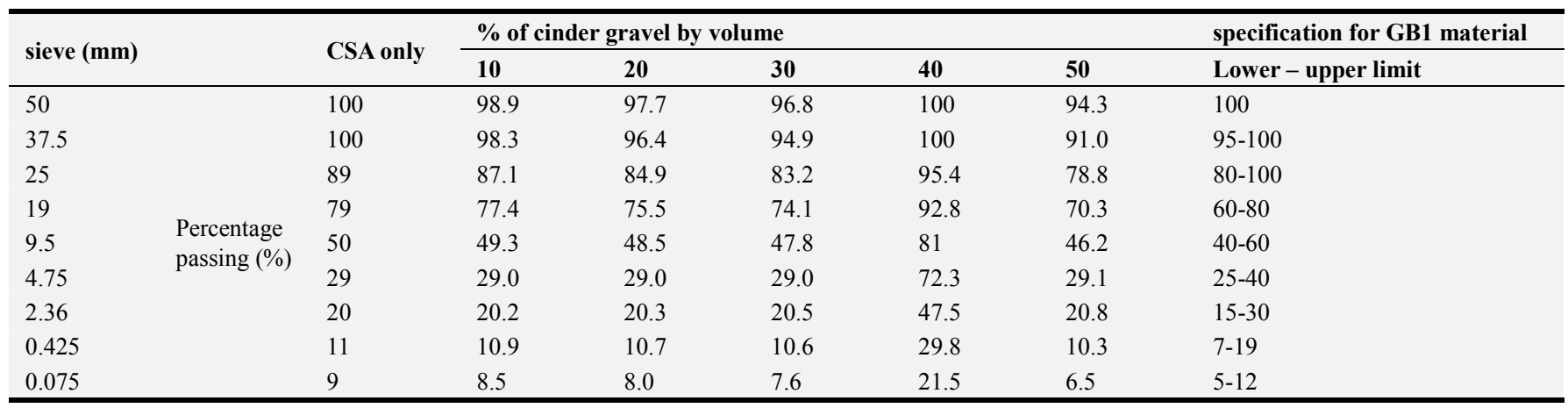

From table 8 it can be seen replacement up to $30 \%$ of CSA with cinder material give promising result in regard to $\mathrm{CBR}$ whereas $40 \%$ could be considered optimum with respect to ACV and TFV requirements set by ERA.

From the above discussions we can conclude that replacing $30 \%$ of conventional CSA with cinder gravel material is a possible alternative in terms of the gradation, strength and shape of particles and also bearing capacity measured by traditional laboratory tests. And this can be regarded as positive because $30 \%$ replacement is significant in terms of saving cost of construction as unit price of cinder gravel is much less than CSA in addition to reducing cost associated with crushing operation.

Table 7. Comparison of gradation of CSA - cinder gravel blends after compaction with the specification.

\begin{tabular}{|c|c|c|c|c|c|c|c|c|}
\hline \multirow{2}{*}{ sieve $(\mathrm{mm})$} & & \multicolumn{6}{|c|}{$\%$ of cinder gravel by volume } & \multirow{2}{*}{$\begin{array}{l}\text { specification for GB1 material } \\
\text { Lower - upper limit }\end{array}$} \\
\hline & & CSA only & 10 & 20 & 30 & 40 & $\mathbf{5 0}$ & \\
\hline 50 & \multirow{8}{*}{$\begin{array}{l}\text { Percentage } \\
\text { passing }\end{array}$} & 100.00 & 100.0 & 100.0 & 100.0 & 100.0 & 100.0 & 100.0 \\
\hline 37.5 & & 100.00 & 99.5 & 99.0 & 97.9 & 97.9 & 97.4 & $95-100$ \\
\hline 25 & & 90.00 & 88.8 & 89.4 & 88.7 & 88.7 & 88.4 & $80-100$ \\
\hline 19 & & 79.90 & 79.0 & 79.8 & 79.7 & 79.7 & 79.6 & $60-80$ \\
\hline 9.5 & & 50.40 & 51.1 & 52.7 & 55.1 & 55.1 & 56.2 & $40-60$ \\
\hline 2.36 & & 20.60 & 21.4 & 23.4 & 26.3 & 26.3 & 27.7 & $15-30$ \\
\hline 0.425 & & 11.40 & 11.4 & 12.1 & 12.9 & 12.9 & 13.2 & $7-19$ \\
\hline 0.075 & & 9.20 & 8.8 & 8.7 & 8.3 & 8.3 & 8.1 & $5-12$ \\
\hline
\end{tabular}


Table 8. Summaries of results of tests conducted on CSA-cinder gravel blends.

\begin{tabular}{lllllllll}
\hline $\begin{array}{l}\text { percentage of cinder } \\
\text { gravel in the blend }\end{array}$ & $\mathbf{0}$ & $\mathbf{1 0}$ & $\mathbf{2 0}$ & $\mathbf{3 0}$ & $\mathbf{4 0}$ & $\mathbf{5 0}$ & $\mathbf{1 0 0}$ & Specification \\
\hline OMC (\%) & 7.6 & 8.9 & 10.6 & 11.24 & 11.75 & 13.23 & 19.44 & NS \\
MDD (g/cc) & 2.32 & 2.19 & 2.15 & 2.13 & 2.08 & 2.05 & 1.77 & NS \\
CBR (\%) & 162.5 & 155.42 & 135.67 & 121.43 & 104.89 & 89.54 & 32 & $>100$ \\
Water absorption (\%) & 0.55 & 4.55 & 4.67 & 4.82 & 5.03 & 5.17 & ND & $1.0-2.0^{*}$ \\
Specific Gravity & 2.6 & 2.5 & 2.4 & 2.4 & 2.3 & 2.285 & ND & $2.5-3.0^{*}$ \\
ACV (KN) & 18 & 21.2 & 23.2 & 26.3 & 29.4 & 33.5 & 35 & $<29$ \\
TFV (KN) & 230 & 203 & 167 & 131 & 114 & 104 & 107 & $>111$ \\
Flakiness index & 18 & ND & ND & ND & ND & ND & ND & $<30$ \\
& ND -not determined & & & & & & \\
\hline
\end{tabular}

\subsection{For Cement Treated Cinder Gravel.}

Determination of the optimum binder content (OBC), so that the stabilized soil fulfills both the strength and durability requirements, is the primary objective of the soil-cement stabilization process. Among the various approach's stabilization guidelines and the requirements that had been specified in BS part: 2 and ERA PDM were employed for determining the OBC.

The minimum acceptable strength of a stabilized material depends on its position in the pavement structure and the level of traffic. It must be sufficiently strong to resist traffic stresses but upper limits of strength are usually set to minimize the risk of reflection cracking.

Table 9. Desirable limits of UCS for cement stabilized materials.

\begin{tabular}{lll}
\hline Standard & & Strength requirements (MPa) \\
\hline Road note 31 [ERA & & $3.0-6.0$ for $\mathrm{CB} 1$ \\
$\mathrm{PDM}$ ] & & $1.5-3.0$ for $\mathrm{CB} 2$ \\
Us army and air force & & 5.2 \\
& \multirow{2}{*}{ Base course } & $2.1-5.17$ \\
National cooperative & & $2.1-4.2$ for A-1, A-2, A-3 \\
highway research & \multirow{2}{*}{ Soil types } & $1.72-3.5$ for A-4, A-5 \\
program & & $1.4-2.8$ for A-6, A-7 \\
\hline
\end{tabular}

\section{Conclusion and Recommendation}

This study was all about studying the physical and mechanical characteristics of cinder gravels to examine their marginality in terms of use their use as base course materials and investigating two possible ways by which they can serve as alternative base course material.

The first part of laboratory investigation showed that cinder gravel is a weak material with an ACV $>30 \mathrm{KN}$ and $\mathrm{TFV}<$ $111 \mathrm{KN}$ also has high water absorption capacity because of its high porosity. The gradation doesn't fulfill the requirement, lacking sufficient fines and having coarser particles more than upper limit of gradation envelop for GB1 material as determined before compaction with Nom. Max. Size 37.5mm. Even if compaction produce fine grained materials to fill the gap it also makes their gradation out of limit due to some fractions of particles were produced more than specified for base course material. The CBR value of the material is very low $(<40 \%)$ for base course. So natural cinder gravels can't be used as base course materials especially for high traffic unless modified in some way.

From Gradation point of view, it has been seen that all the blend proportions satisfy requirements for dense graded base course as determined in after compaction state. Whereas with regard to particle strength and bearing capacity (shear resistance) the one containing $30 \%$ cinder gravel by volume of the total blend fulfill the criteria by attaining ACV of $26 \%$ $<29 \mathrm{KN}$ and CBR of $121 \%$ (satisfying well above 100 criteria). Thus, we can conclude that replacing $30 \%$ of conventional CSA with cinder gravel material is a possible alternative in terms results of the gradation, particle strength and also bearing capacity as measured by common laboratory tests.

Cement stabilization can be regarded as one of the many ways to improve the properties of cinder gravels so as to make them suitable for base course construction materials. Optimum (minimum) cement content fulfilling strength requirement of Road note 31 for $\mathrm{CB} 1$ is $8 \%$ and for $\mathrm{CB} 2$ it is $6 \%$. The only mix satisfying criteria by US army was the one containing $10 \%$ cement by weight of dry cinder gravel. The compressive strength of cinder - cement mix increases with curing age and also cement content. Soaking specimens in water decrease the strength of the mix only in the case of mix having $6 \%$ cement whereas for the others it was observed that the strength increase in small amount, which indicates cindercement mix with 8 and $10 \%$ cement are not susceptible to moisture change.

Based on literatures reviewed during the study and the outcomes of the study Based on the results of the research, it is recommended for consultants (designers), contractors and local and national road authorities that utilization of the locally available cinder gravels shall be given due consideration for upcoming road construction projects in the study area or in other locations with similar characteristics.

Although the study indicated that cinder gravel materials collected from Sallo, Tullu dimitu and Debrezeit gives promising result as a partial replacement to conventional base course material, CSA, even for highly trafficked roads i.e. GB1, samples should be collected from other sources found in many parts of Ethiopia so as to prepare guidelines for their use.

This study uses traditional/common laboratory test methods to investigate the properties of materials so determining the 
mechanical properties of CSA - cinder gravel blends and cement treated cinder gravels through state-of-the-art laboratory test which enable to design the thickness of base course layer incorporating these materials is suggestion for future studies.

Since laboratory results only predict field performance the exact performance of cinder gravels either blended with conventional base course (CSA) or treated with cement should be studied in as built condition by full scale experiments through constructing trial sections along areas having large distribution of cinder cones.

\section{References}

[1] Newill, d., Robinson, r. And kassaye Aklilu. "Experimental use of cinder gravels on roads in Ethiopia". 9th regional conference for Africa on soil mechanics and foundation engineering / Lagos, September 1987.

[2] Ethiopian roads authority. "pavement design manual volume I: flexible pavements", 2013.

[3] Ethiopian roads authority. "Site investigation manual", 2011.

[4] Birhanu Girma. "Stabilizing cinder gravels for heavily trafficked base course". Journal of EEA. 2009; vol. 26.

[5] Dinku, Abebe, "The need for standardization of aggregates for concrete production in Ethiopian construction industry"). International conference on African development archives. (2005); paper 90.26.

[6] National lime association. "Lime-treated soil construction manual: lime stabilization \& lime modification", January 4, 2010 .

[7] J. b. oza, Dr. P. J. Gundaliya. "Study of black cotton soil characteristics with cement waste dust and lime" Non-circuit branches of the $3 \mathrm{rd}$. Nirma university international conference on engineering. 2013; pp. 110-118.

[8] Das. M. B. "Fundamentals of geotechnical engineering". Toronto, Canada: Nelton; 2005.

[9] Martin R. "Highway pavement materials and design". In: Martin R, 1st. High way engineering. UK: 2003; 192-228.

[10] D. N. Little and R. Graves, "Upgrading Marginal Aggregate Bases and High-Fines Bases with Low Levels of Stabilizers", Texas Transportation Institute, Texas A\&M University and Vulcan Materials.

[11] Jean Chorowicz." The east African rift system". Journal of African earth sciences. 2005; 43: 379-410.
[12] John Murray Hudson. "The behavior of road base materials under repeated loading". Thesis submitted to doctor of philosophy. October 1971.

[13] W. Spencer. G., B. Mathew. R and I. Dennis. E." Evaluation of laboratory durability tests for stabilized aggregate base materials": Transportation research board 87th annual meeting: Portland cement association; 2007.

[14] Engidasew, T. Engineering geological characterization of volcanic rocks of Ethiopian and Sardinian highland. $\mathrm{PhD}$ in soil defense and conservation; 2012/2013.

[15] Efrem, G. "Stabilization of cinder with foamed bitumen and cement and its use as (sub) base for roads." International institute for infrastructural, hydraulic and environmental engineering. 2000 delft; M. Sc. thesis TRE 100.

[16] Department for International Development (DFID), of the UK and the Department of Public Works and Highways (DPWH), Philippines." Literature review on stabilized sub base for heavily trafficked roads". Project report origin PR/INT/202/00.

[17] Toolet and d Newill. "A strategy for assessing marginal quality for use in bituminous roads in the tropics". Summer annual meeting, university of bath. September 1987: 1-27.

[18] J. R. Cook and C. S. Gurley. "A framework for the appropriate use of marginal materials". World road association (PIARC)-technical committee c12 seminar in Mongolia, TRL. Ltd, UK: June 2002.

[19] AASHTO, "Standard Specification for Transportation Materials and Method of Sampling and Testing", Part 1 Specifications, 20th Edition, American Association of State Highway and Transportation Officials. Washington D. C, 2000.

[20] B. Gautama, D. Yuan, I. Abdalla and S. Nazarian. "Guidelines for Using Local Materials for Roadway Base and Sub base". Center for Transportation Infrastructure Systems. The University of Texas at El Paso. 2009 association for computer methods and advances in geo-mechanics. 2008.

[21] American association of state highway and transportation officials. Stabilization of subgrade soils and base materials AASHTO designation. 2008.

[22] Cook J., Bishop E., Gurley C. and Ellsworth N. Promoting the use of marginal materials. Project report PR/INT/205/.2001.

[23] Donatas C., Alfredas L., Audrius V. and Virgaudas P. Research of experimental road pavement structures. The $25^{\text {th }}$ international symposium on Automation and Robotics in road construction. June, 2008.

[24] A. A. Araya. Characterization of Unbound Granular Materials for Pavements. Master of Science in Transport and Road Engineering. 2011; IHE/TU Delft, the Netherlands. 